\title{
TerrorScale: A Scale to Measure the Contact of International Tourists with Terrorism
}

\author{
Cláudia Seabra \\ Higher School of Technology and Management \\ Polytechnic Institute of Viseu, Portugal \\ E-mail: cseabra@estv.ipv.pt \\ José Luís Abrantes \\ Higher School of Technology and Management \\ Polytechnic Institute of Viseu, Portugal \\ E-mail: jlabrantes@estv.ipv.pt \\ Elisabeth Kastenholz \\ Aveiro University, Portugal \\ E-mail: elisabethk@ua.pt
}

\begin{abstract}
Terrorism is unfortunately part of our lives and will not simply disappear. Accepting its presence, the management and prevention of its negative consequences is a key issue. This is imperative not only for countries where terrorist attacks occur, but also for countries that may be affected indirectly. It is necessary to further consider this issue and create more effective instruments for crisis management, ideally based on cooperative solutions among industry, government agencies and tourism-related academic institutions (Sönmez, 1998). Although research on terrorism has been undertaken in the tourism domain, the specific concept of tourists' contact with terrorism has never been operationalized. In this paper we develop a scale that measures the contact of tourists with terrorism. Insights from an empirical study of 600 international tourists indicate that this multi-dimensional scale incorporates three types of contact: 1) Direct, 2) Indirect and 3) Attention to/ Interest in Terrorism on the Media. Discussion centers on implications of this scale for theory development and in the context of strategic destination crisis management decisions . Directions for future research are also presented.
\end{abstract}

\section{Keywords}

International tourism, terrorism, travel decision making, mass media, risk perception 


\section{Introduction}

The globalization of the tourism industry has led to a rapid expansion of tourism businesses at an international scale, implying this worldwide industry's growing exposure to a series of "global risks". On the other hand, the world is becoming increasingly interdependent, with small scale crises in one part of the world eventually triggering consequences in other parts. The tourism industry, although not being the only vulnerable sector, is undoubtedly highly exposed to risks and sensitive to crises provoked by external events. In contrast to internal events, controllable by managers, external ones are beyond control and induce naturally higher levels of perception of risk and uncertainty (Evans \& Elphick, 2005). Violent crimes of social (murders, violations and armed thefts) or political nature (terrorism, political confrontation) provoke travel anxiety amongst tourists, regarding both general travel abroad and particularly travel to specific destinations which are perceived as less safe. Violence affects in a direct way a country or destination image, destroying both internally and internationally a society's functioning and well-being, and seriously interfering with the free flow of people and ideas. When people feel fear of travel, isolation and xenophobia may be the result and both cooperation and cultural exchange may come to an end (Pizam, Tarlow \& Bloom, 1997).

Contrary to expectations, the end of the Cold War did not mark the beginning of an era of peace. In the recent past, there is a proliferation of armed conflicts all over the world. Geopolitical changes are largely connected to the evolution and increase of terrorism (Cutter \& Wilbanks, 2003; Le Billon, 2001). The global geopolitical situation has changed after the Berlin wall fall. Additionally, the economic, social, technological and cultural repercussions of globalization have influenced the evolution of terrorism, both in its national and transnational dimension. Terrorist organizations have, in fact, become global actors, supported by organizations, such as multi-national companies and nongovernment organizations (Bravo \& Dias, 2006). Terrorist groups have become more sophisticated, dangerous and destructive (Gupta et al., 2004) and their attacks have become more indiscriminate. Terrorism is nowadays an institutionalized reality and has spread geographically as a method of armed conflict. In fact, terrorism is observed today in a more intense degree than in any moment in history (Sönmez \& Graefe, 1998b). Terrorists will continue to select vulnerable and defenceless targets (Atkinson, Sandler \& Tschirhart, 1987) andtourists are becoming increasingly appealing targets, in this context. A terrorist attack aiming at tourists may help terrorists achieve their diverse objectives: publicity of their "cause", economic threat, ideological opposition to tourism, amongst other aspects (Sönmez, 1998).

The attention that mass media pay to terrorist attacks, perversely, confirms the utility of tourism to terrorism (Richter, 1983). Whenever tourists are victims of terrorism, the situation is immediately covered by the media and the political conflict is transferred to a much larger scale, receiving international attention. The tourists' country of origin is involved in the situation and the subsequent involvement of other countries intensifies the pressure on the government to which terrorists intend to send their messages (Sönmez \& Graefe, 1998b). In a social and cultural perspective, the travellers are seen as ambassadors of their countries, which in many cases, personify the values that terrorists want to fight. The economic disruption caused by the drawbacks in the tourism industry and associated sectors also helps terrorists achieve their economic objectives (Sönmez \& Graefe, 1998a).

Tourism suffers indeed with the terrorism activity. Terrorist attacks affect tourists' perceptions, particularly when terrorist organizations yield specifically targets within the tourism industry (Sönmez, 1998). The fear and anxiety regarding the possibility of terrorism and lack of safety in the tourism context, further enhanced by media coverage (sometimes in an exaggerated manner), have clearly impacted negatively on tourist demand of many destinations. Even if the threats of instability and violence reveal themselves as baseless, their impact may be severe (Baral, Baral, \& Morgan, 2004). Terrorism, wars and political unrest have immediate negative consequences in some destinations (Russel \& Faulkner, 2004). If we consider tourists to be rational consumers who guide their decisions by comparing costs and benefits, the increased cost of a tourist experience facing the threat of terrorism is easy to understand (Sönmez, 1998). The increased perceived risk makes, 
consequently, tourists seek substitute destinations that are considered safer (Enders \& Sandler, 1991; Enders, Sandler, \& Parise, 1992; Gu \& Martin, 1992).

Some recent occurrences prove this negative influence of conflict situations on tourist demand: the Golf War impacting tourism in the Middle East, Mediterranean and Southern Europe; the terrorist attack directed at Luxor in Egypt in 1997 impacting on tourism in the Mediterranean region; the Kosovo conflict with serious repercussions on tourism in Eastern Europe; the September 11 attack in the USA, with disastrous effects on air travel worldwide, the list is long, indeed (Blake \& Sinclair, 2003). The recent incidents have, unfortunately too late, alerted the world concerning the terrible consequences that terrorist acts may have in an increasingly global and globalizing economy.

It is true, that it is probably impossible to control terrorism, but the nations cannot ignore the phenomenon. Governments, enterprises and tourism institutions need to focus their attention on this threat so as to generate effective marketing strategies that helpcope with it and its consequences (Hall \& O'Sullivan, 1996). Destinations need to elaborate specific action plans, in the light of recent incidents and the global complexity of the phenomenon (Sönmez, 1998).By their very nature, crises resulting from terrorist attacks are chaotic and not all their contingencies may be covered, but it would be prudent to prepare and plan for this kind of situations (Evans \& Elphick, 2005).

The awareness of the human costs associated to the recent terrorist incidents and the corresponding reallocation of economic resources, presumably motivated by the risk of future terrorist attacks, have led to a concentration of efforts of several organizations aiming at a better understanding of terrorism and its consequences (Blomberg, Hess \& Orphanides, 2004). The increased exposure to political, economic, social and technological changes obliges companies and managers who work in tourism to be more aware and capable of dealing with imminent crises. By thoroughly understanding the terrorism phenomenon and its repercussions it is possible to develop more effective strategies to stop or reduce the severity of its impacts on the economy and society (Ritchie, 2004). Organizations of any kind and dimension will have to cope with change in any point of their life cycle and all destinations will have to face crisis at some point in time (Faulkner, 2001).

Some authors state that there is little research about the crisis phenomenon in the tourism industry (Faulkner, 2001) and some issues have been neglected, such as the concept of "contact with terrorism", which has never been operationalized for the international tourism sector, despite its apparent relevance. However, it becomes imperative for tourist destination marketers to understand the perceptions and attitudes of tourists facing terrorism for developing marketing strategies that prevent or solve crisis situations in which a positive destination image needs to be recovered (Sönmez, 1998). In this context, it is most important to understand and measure the different types of contact that tourists have with terrorism to be able to understand their potential impact on tourists' attitudes and behaviours and correspondingly guide management and marketing action.

The results here presented will hopefully contribute to the progress of tourism theory by developing an empirical methodology that permits the assessment of the tourists' contact with terrorism. On the other hand, the development of this measurement instrument may equally contribute to an improved management of tourism organizations by facilitating the development of more effective communication campaigns directed at tourists.

The paper is organized as follows. Starting with an overview of literature, in the second part, the three dimensions of the TerrorScale are presented. Thirdly, the scale is tested via survey of 600 international tourists travelling by plane. Research limitations and future directions are also presented. Finally, implications for tourism theory and practice are discussed.

\section{Literature Review}

The threat of danger related to terrorism or political instability intimidates more than any other natural or human disaster (Sönmez, 1998). The psychological impact of terror may be less induced by its destructive power than by its potential to evoke fear and anxiety (Spilerman \& Stecklov, 2009). Fear of terrorism is irrational, though, and the probability of a tourist becoming involved in a terrorist 
incident is minimal (Sönmez, Apostolopoulos \& Tarlow, 1999), but physical threats, real or perceived, are sufficient to significantly impact on tourist perceptions and consequent behaviour.

The increase of terrorist incidents has increasingly concerned researchers. In fact, the proliferation of terrorism coincides with a growing number of studies on the topic. The first peak of terrorist incidents was observed in the 1980s (D'Amore \& Anuza, 1986; Richter \& Waugh, 1986). The Golf War and the possibility of related terrorist attacks have called for renewed research attention. Effectively, although the incidents occurred in relatively small number, they were larger in magnitude, in the last two decades (Sönmez, 1998). The terrorist attacks of September 11th in the USA and all following terrorist attacks have inflamed the discussion of the topic again.

Studies that analyze the tourist sector affected by violent political incidents conclude that terrorism threatens tourism (see Brady \& Widdows, 1988; Enders \& Sandler, 1991; Enders, Sandler \& Parise, 1992; Hurley, 1988; Tremblay, 1989). There is a substitution effect between destinations, whenever terrorism - or the threat of it occurring - becomes evident (Gu \& Martin, 1992). Risk perception is strongly related to the fact of tourists avoiding certain regions, for example, those who are more aware of the terrorist risk avoid travelling to the Middle East (Sönmez \& Graefe 1998a, 1998b).

Tourists dispose nowadays of such a large quantity and variety of choice for their travel purposes that they normally do not even consider the hypothesis of travelling to locations which may be victims or are geographically close to destinations with perceived risk of violent incidents. A destination is, in this context, quickly substituted by another similar alternative. Travelers prefer waiting until the situation in the country, they initially considered as a destination, comes back to normal. These situations cause important negative economic effects at the affected destinations (Sönmez, Apostolopoulos \& Tarlow, 1999).

Tourism demand is particularly sensitive to tourists' concerns regarding safety, health and general well-being (Blake \& Sinclair, 2003). Due to the intangible nature of the tourist experience, the selection of tourist destinations and activities depends largely on the positive perceptions associated to the destination before travelling. Destination image is, indeed, a crucial factor when selecting a destination and correspondingly an essential point in tourism marketing (Bramwell \& Rawding, 1996; Chon, 1991; Dann, 1993; Echtner \& Ritchie, 1991; Gartner, 1989). During the decision making process, the potential tourists compare products according to costs and benefits perceived (Crompton, 1979; Enders \& Sandler, 1991; Enders, Sandler \& Parise, 1992; van Raaij \& Francken, 1984; Woodside \& Lysonski, 1989). Some destinations may be eliminated due to their potential cost or perceived risk, especially if they are associated by the mass media to terrorism or other situations of insecurity (Sönmez, 1998).

Indeed, many authors analyzed the impacts that the perceived risk of terrorism has on tourist behavior. Many studies have concluded that tourists, especially those traveling internationally to more distant destinations, cancel their travel plans or change them if they feel risk of terrorism (D'Amore \& Anuza, 1986; Coshall, 2003; Evans \& Elphick, 2005; Hartz, 1989; Hurley, 1988; Sönmez \& Graefe, 1998a, 1998b; Spilerman \& Stecklov, 2009; Uriely, Maoz \& Reichel, 2007). Another conclusion across several studies is that domestic tourists can be an important source of consumers in tourist crisis arising from terrorist attacks (Fleischer \& Bucola, 2002; Paraskevas \& Beverley, 2007; Sönmez, 1998; Sönmez \& Graefe, 1998a, 1998b; Yechiam, Barron, \& Erev, 2005). Also, several studies concluded the negative effect of terrorism on tourism revenues in many destinations (Brady \& Widdows, 1988; Krakover, 2000; Neumayer, 2004; Tremblay, 1989)

The fear of terrorism may exist in tourists due to many factors: past experiences with terrorist attacks, conflict proximity, tourist destination negative image, social interaction and influence of agents and tour operators (Sönmez \& Graefe, 1998a) and exposure to information from the media (Seabra, Abrantes \& Lages, 2007). In this study, two major types of terrorism contact were considered: direct and indirect contact with terrorism and attention to/ interest in terrorism transmitted in the media, as described in detail in the following points. 


\subsection{Direct Contact with Terrorism}

Crime may be defined as an "an act committed or omitted in violation of a law forbidding or commanding it" (Black, 1979, p.334 in Pizam, 1999) and violence as "an unjust or unwarranted exercise of force, usually with the accompaniment of vehemence, outrage or fury" (Black, 1979, p.1408 in Pizam, 1999). Both concepts must be considered since, in many cases, violent acts are viewed as crime, such as an assault, agression, violation, murder, amongst others. In other cases, violent acts like international wars, civil wars, upheaval, tumults, political protest and terrorism are considered by some as criminal acts, by others as "glorified acts of struggle for freedom or liberation" (Pizam, 1999, p. 5).

Some authors state that experiences with crime may contribute to the existence of psychological disorder, underlying the individuals' risk perceptions. These would interact with the physical and social vulnerability of the persons in question as well as with their tendency to generate certain levels of fear and anxiety (Hough 1995 in Brunt, Mawby \& Hambly, 2000). The physical proximity of traumatic events, such as terrorist attacks, is correlated with the probability of symptoms of trauma an individual may suffer (Schelenger et al., 2002; Schuster et al., 2001). Nevertheless, also individuals who have not directly experienced these events may reveal the same symptoms (Pfefferbaum et al., 1999; Schelenger et al., 2002; Schuster et al., 2001). In the real world context, the contact with terrorism is part of the daily life of individuals in two manners (Sommer et al., 2005): directly, by being present when an attack occurs, becoming injured due to a terrorist incident or by participating in rescue operations; indirectly, by feeling to have escaped a terrorist attack due to luck, by having been at the site shortly before the incident occurred, by having provided any kind of aid or by knowing people who have excperienced terrorist incidents in the past.

\subsection{Attention to/ Interest in Terrorism on the Media}

Mass media transmit news during the periods of crisis and it is a fact that the majority of the audience consider negative, even dramatic reports much more interesting than positive news. Media do understand this phenomenon and consequently tend to explore the negative aspects of reality (Cavleck, 2002). In this line, media assume a fundamental role in terrorist activities. Terrorists use mass communication channels to transmit their message to the largest possible audience, since media base their information activity on real time transmission in times of crisis (O'Connor, Stafford \& Gallagher, 2008). Some authors defend that the perceived contact with terrorism would be, since the 1970s, closely connected to the development of excessive media coverage of the phenomenon (Sönmez \& Graefe, 1998a).

As a whole, media ensure that any terrorist act enters immediately a global domain (Sönmez, 1998). In fact, Taylor (2006) and Sönmez (1998) cite a seminal work by Karber (1971) who states that terrorism is a symbolic act that can be analyzed as any other communication medium. This definition is based on four basic communication process components: sender (terrorist), message intention (terrorist target), message (terrorist act) and feedback (reactions to the attack) (Karber, 1971 in Sönmez, 1998).

As a consequence for tourism, the media exploration of terrorist attacks potenciates the creation and transformation of public images held on tourism, particularly international travel (Sönmez, 1998) and specific destinations or entire regions. The power of media may even change pre-existing images and attitudes. This power is due to the fact that, in many cases, the mass communication means are the only source of information available to the audience. Even if the mass media are not the exclusive source, they are at least considered the most important for interpreting facts, terrorist motives and the implications of their actions (Weimann \& Winn, 1994). Tourists, in turn, reveal a high level of interest and dedicate considerable attention to news regarding terrorism, retaining in memory information about this type of events (Jin, 2003). 


\section{METHODOLOGY}

\subsection{The research setting and purpose}

The research setting refers to a survey approach, applied in three European countries (Portugal, Spain and Italy) in an international tourism context, more specifically in an international air travelling context. The specific aim of this study is to build a scale to measure the different types of contact that international tourists have or had with terrorism.

Our proposition is that tourists can experience several types of contact with terrorism:
a) Directly
b) Indirectly
c) Trough Media Attention and Interest.

\subsection{Development of the survey instrument}

A scale to capture the types of contact that international tourists have with terrorism was developed. Due to the inexistence of any scale to measure the contact of terrorism in the tourism research, an initial version of the instrument was developed using scales previously established in other study fields, namely Sommer et al. (2005) to measure direct and indirect contact and Jin (2003) to assess Attention to/Interest to Terrorism in Media.

Sommer and his colleagues (2005) analyzed the level of exposure to terrorism of individuals residing in the affected areas of 2001-2002 terror campaign against Israel's heartland. The authors also examined psychological responses and ways of coping during the peak of the violence. The initial scale suffered some changes to adapt the scale to the study setting (see Appendix 1).

To measure Attention to/Interest to Terrorism, it was used a scale by Jin (2003). The author examined the effects of Super Bowl advertising campaigns information in news stories on consumer's memory of the subsequent ads. In order to address the memory of advertising ads, the author used a scale to analyze Interest, Attention and Memory. In the present study it was used only the Interest and Attention dimensions, the scale was adapted to measure the attention to and interest to terrorism news reports in media (see Appendix 1).

These scales were then discussed with people capable of understanding the nature of the concept being measured. We translated the initial scales into three languages: Portuguese, French and Spanish and then the instrument was back-translated to English. All the items were assessed through a seven-point Likert-type scale (see table 1). After revisions, we used a pre-test sample of 30 international travelers in order to test the reliability of the scales (through Cronbach alpha). The pre-test results were used to further refine the questionnaire.

\subsection{Data Collection}

The final data was collected from January 2009 to March 2009. Tourists who agreed to participate in the study were randomly selected, in loco, across three international airports: Madrid ( Barajas), Lisbon (Portela) and Milan (Malpensa). Only those tourists were interviewed who had undertaken an international trip, i.e. tourists that had travelled to a country different from their own. Two of the study's authors administered the questionnaires personally, explaining the aim of the study to respondents at the moment after they checked in for their return trip. The questionnaire was selfadministered, ensuring anonymity, and thus eliminating interviewer bias as well as the likelihood of socially desirable responses. To reduce other potential biases, data was collected on the last Friday, 
Saturday, and Sunday of each month from 5.00 am to $5.00 \mathrm{pm}$. At Barajas airport/ Madrid, the data was collected in January; at Malpensa airport/ Milan, in February; and at Portela airport/ Lisbon, in March 2009. This ensured that business or leisure travelers were not the only persons interviewed. Potential respondents were also asked if they had sufficient time to complete the survey, in order to ensure that they would not be forced to rush through the questionnaire to catch their flight, which would have compromised data quality. A final sample of 600 valid responses was obtained, which was equally divided among the three international airports.

\subsection{Profile of respondents}

Tourists in this study sample were from 41 countries all over the world. The sample was composed of slightly more men (56\%) than women, with ages mostly under 35 years (56\%). Approximately $74 \%$ had university education, $22 \%$ were middle and senior management, $20 \%$ were businessmen, about $19 \%$ were freelancers/ self-employed and $15 \%$ students. The individual average monthly income ranged from 2000 to 3000 Euros. The sample was mainly composed of frequent travelers, who had undertaken, on an average, seven international trips in the last three years, lasting nine days each. There was a relatively high degree of familiarity with the destination visited, since tourists had on average visited the destination 3.5 times before. Each tourist used, on average, 15 days to plan the trip, and referred to reservations planning with a period of 25 days in advance.

\section{DATA ANALYSIS}

\subsection{Confirmatory factor analysis}

In order to assess the validity of the measures, the items were subjected to a confirmatory factor analysis (CFA), using full-information maximum likelihood (FIML) estimation procedures in LISREL 8.8 (Jöreskog \& Sörbom, 1996). In this model, each item is restricted to load on its pre-specified factor, with the three first-order factors allowed to correlate freely. After CFA purification, the initial list of 12 items was maintained. A full listing of the 12 final items after CFA purification and their scale reliabilities is shown in Table 1.

The chi-square for this model is significant $\left(\chi^{2}=336.21,51 \mathrm{df}, \mathrm{p}<.00\right)$. Since the chi-square statistic is sensitive to sample size, we also assessed additional fit indices: Normed Fit Index (NFI), Comparative Fit Index (CFI), the Incremental Fit Index (IFI), and the Tucker-Lewis Fit Index (TLI). The NFI, CFI, IFI and TLI of this model are $.95, .96, .96$, and .95 , respectively.

As can be seen in Figure 1, convergent validity is evidenced by the large and significant standardized loadings of each item on its intended construct (average loading size is 0.83). As shown in Table 1, all constructs present desirable levels of composite reliability (Bagozzi, 1980). Discriminant validity among the constructs was stringently assessed using the Fornell and Larcker (1981) test; all possible pairs of constructs passed this test (Table 1); more specifically, the average variance extracted was above the recommended level of 0.50 for all three constructs. Evidence of discriminant validity was also revealed by the fact that all the constructs' inter-correlations were significantly different from 1 the highest is for TSC1 and TSC2, 0.472 - and the shared variance between any two constructs (i.e. the square of their inter-correlations) was less than the average variance extracted for each construct.

Hence, none of the correlations in the final model was sufficiently high to jeopardize the constructs' discriminant validity (Anderson \& Gerbing, 1988). 


\section{Figure 1: The TerrorScale- Constructs and standardized coefficients}

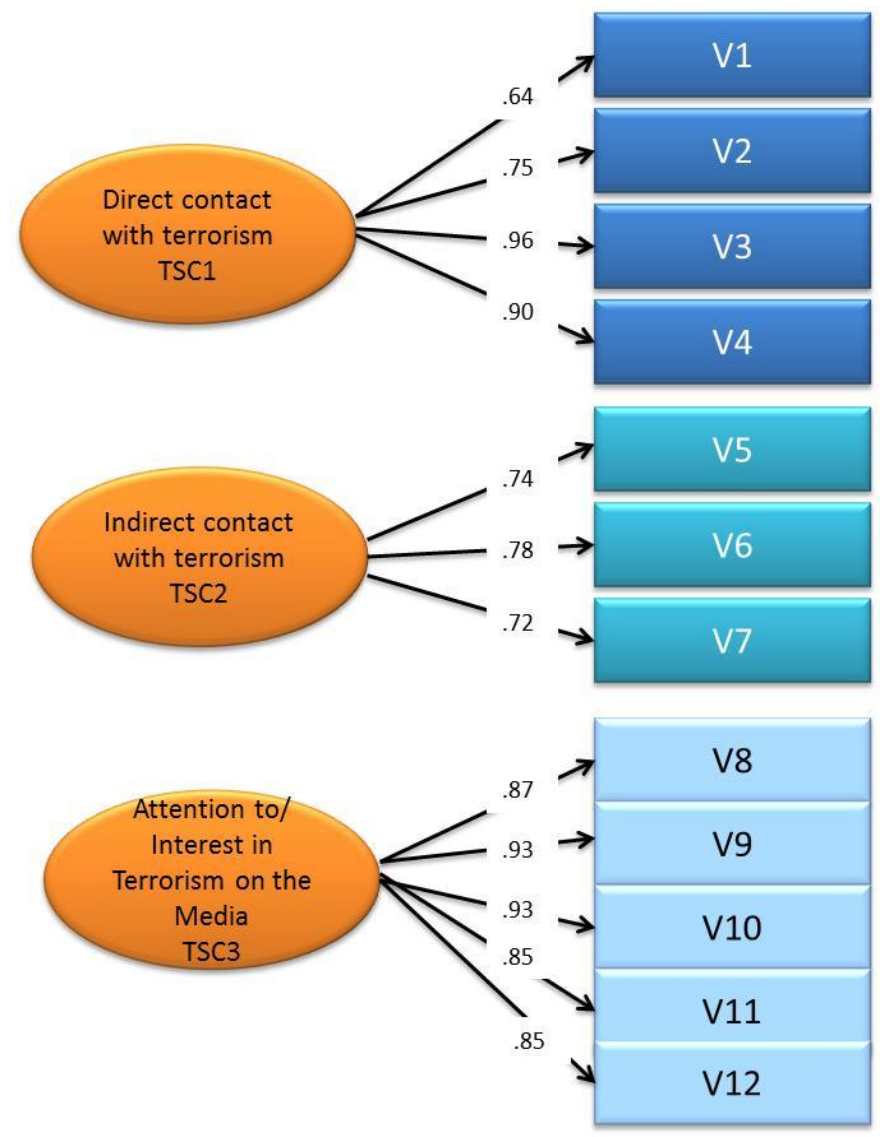

Table 1: The TerrorScale- Constructs, scale items, reliabilities and T-Values

\begin{tabular}{|c|c|c|}
\hline & Constructs, Scale Items and Reliabilities & T-values \\
\hline \multicolumn{3}{|c|}{ TSC1- Direct Contact with Terrorism $\left(\alpha=.881 ; \rho=.89 ; \rho_{\mathrm{vc}(\mathrm{n})}=.68\right)$} \\
\hline V1 & I was present on the scene during a terrorist attack & 17.26 \\
\hline V2 & I was physically injured by a terrorist attack & 21.01 \\
\hline V3 & I was on site as a first responder & 30.79 \\
\hline V4 & I provided either physical or emotional aid in a terrorist attack & 27.73 \\
\hline \multicolumn{3}{|c|}{ TSC2- Indirect Contact with Terrorism $\left(\alpha=.779 ; \rho=.79 ; \rho_{\mathrm{vc}(\mathrm{n})}=.56\right)$} \\
\hline V5 & I was exposed to the damaged site shortly after a terrorist attack & 18.66 \\
\hline V6 & I know somebody who was on site during a terrorist attack & 20.14 \\
\hline V7 & I escaped a terrorist attack by luck & 18.11 \\
\hline \multicolumn{3}{|c|}{ TSC3- Attention and Interest to Terrorism on Media $\left(\alpha=.947 ; \rho=.97 ; \rho_{\mathrm{vc(n})}=.78\right)$} \\
\hline V8 & I am really interested in terrorist attacks reports on news & 26.61 \\
\hline V9 & $\begin{array}{l}\text { When I have the opportunity I watch/read/listen to reports about terrorist attacks on } \\
\text { the news }\end{array}$ & 29.67 \\
\hline V10 & I am very curious about terrorist attacks reports on the news & 29.77 \\
\hline V11 & I do not want to miss terrorist attacks reports on the news & 25.64 \\
\hline V12 & I pay much attention on reports about terrorist attacks on the news & 25.61 \\
\hline
\end{tabular}

Notes:

$\alpha=$ Internal reliability (Cronbach 1951); $\rho_{=}$Composite reliability (Bagozzi, 1980); $\rho_{\mathrm{vc}(\mathrm{n})}=$ Variance extracted (Fornell \& Larcker, 1981);

The TSC1 and TSC2 scales are anchored by "1- Never" and "7- Many times", TSC3 was assessed with a scale ranging between "1 - Strongly Disagree" and "7 - strongly agree". 


\subsection{Nomological validity}

In order to assess nomological validity, we tested our measures with respect to some other constructs to which our construct is supposed to be theoretically related (cf. Churchill, 1995). According to the tourism literature, there are well-grounded theoretical reasons to expect a positive relationship between all constructs of the suggested TerrorScale and "Risk Perceptions".

Considering the features of the tourism service/ experience evaluated, the tourists establish during their decision making process, a trade-off between costs and benefits in order to achieve the best possible choice (Um \& Cromtpon, 1992). Apart from financial costs, typical to a trip (associated to expenditures in transportation, accommodation, food and entertainment) tourists may incur psychological, social and time risks (Rohel \& Fesenmaier, 1992). Another cost factor, particularly associated to international travel, is physical risks (diseases, accidents, crime or terrorism and even death) (Enders \& Sandler, 1991; Enders, Sandler \& Parise, 1992).

The terrorism-related risk perceptions that tourists associate with destinations and international trips are based on a variety of factors, including previous experiences, the context in which incidents occurred and the way in which media transmit these events and maintain them alive in the individuals' minds (Fletcher \& Morakabati, 2008).

For assessing risk perception associated to international travel, a scale based on Sönmez and Graefe (1998b) was used, containing four items (possibility of becoming sick while travelling or at the destination; possibility of physical danger or injury detrimental to health like accidents; possibility of becoming involved in the political turmoil of the country being visited; possibility of being involved in a terrorist act), and using scales ranging from 1 - very low risk, to 7 - extremely high risk. This scale revealed an Cronbach's Alpha of .882.

Hence, in our study, nomological validity would be demonstrated, if the scores of all of the three TerrorScale components are positively and significantly correlated with the risk perception. The correlations between risk perception and TSC1, TSC2, TSC 3 are $.084, .087$ and .214 respectively. All the correlation coefficients are significant (TSC1 and TSC2 at $\mathrm{p}<.05$ and TSC3 at $\mathrm{p}<.001$ ). Since this a much greater proportion than would be anticipated by chance, we may conclude that the here presented TerrorScale contributes significantly to risk perceptions and, accordingly, the nomological validity of the 3 proposed measures is supported (cf. Cadogan, Diamantopoulos \& Mortanges, 1999; Cross \& Chaffin, 1982).

\section{Conclusions, Discussion and Implications}

Terrorism has unfortunately become a constant part of our lives and will not simply disappear. It is thus fundamental to accept its presence and inevitability for effectively coping with the phenomenon from a managerial point of view. This is imperative not only for countries that directly suffer terrorist attacks, but also for countries that may be indirectly affected and for the tourism industry as a whole. It is therefore necessary to better analyse this issue and create more effective crisis management tools, based on cooperative solutions among members of the industry, government entities linked to tourism as well as academia (Sönmez, 1998).

Given the already high complexity of the tourist decision making process, a high risk perception associated to an event that should be pleasant is, in fact, problematic (Taylor, 2006). It is also clear that risk perceptions are highly subjective in nature and frequently do not reflect real risk. That is why the development of an appropriate marketing strategy is a fundamental part of destination management, especially of those destinations in greater risk of being affected by terrorism. and particularly in times of real crisis. Crisis management in face of terrorism is an area of particular importance to managers, since, unfortunately, contact with terrorism occurs in nowadays daily life, directly, indirectly or trough media, influencing many consumers' and tourists' decisions (Baral, Baral \& Morgan, 2004; Sönmez, 1998; Sönmez, Apostolopoulos \& Tarlow, 1999; Sönmez \& Graefe, 1998a, 
1998b). The selection of a strategy for tourism depends on how tourists perceive the risk and the contact that they had with terrorism.

In this paper we develop a scale that measures the various types of contact that tourists may have with terrorism. Typically researchers have investigated only the influence that terrorism and the associated perceived risk have on tourists' decisions. However, by focusing on assessing different types of contact that tourists have with terrorism we hope to achieve an important contribution to both theory and management practice.

It is expected that through the application of the TerrorScale, together with other variables, in the context of market studies, tourism firms may better understand the type of contact tourists have with terrorism and how it impacts on tourists' decision making. Different types of tourists, with distinct sensitivity towards and fear of terrorism may be identified, based on distinct patterns of prior contact with terrorism, resulting in different travel behavior (Seabra et al, 2012). By understanding these phenomena and measure the different contact of tourists with terrorism, tourist organizations' managers will benefit from this scale:

- Destination managers may use a framework to develop and implement strategies that might reduce perceived risk and increase the value associated with destinations and their services, targeting to specific types of tourists and adapting communication strategies and materials depending on the level of tourists contact with terrorism emphasizing more or less safety issues.

- Tourist organization managers, namely hotels and resorts managers can understand tourists needs regarding safety issues towards terrorism and design their services in accordance with those needs.

- Tourism Operators may use this scale to implement strategies to attract and to satisfy different tourist targets according to their contact and sensibility towards terrorism.

The TerrorScale dimensions might thus provide some guidance on how to better pursue an information-oriented business strategy. By identifying tourists' levels of contact with terrorism it becomes possible to make choices regarding marketing strategy, such as identifying different market segments and correspondingly differentiated strategies, or improving the destination's positioning. The scale developed here may, in fact, be used as a basis for the segmentation of a tourist market and corresponding marketing decisions (Seabra et al, 2012).

From a theoretical perspective, to our knowledge, a measurement scale to assess contact with terrorism has never been operationalized in a tourism context. Although we cannot claim to have definitively captured all dimensions of terrorism contact, we believe that we come closer to capturing these overall evaluations by extracting the underlying commonality among dimensions. We hope that the TerrorScale presented here contributes to both the tourism and the service marketing literature. In sum, at a time when marketing researchers are challenged to provide research with practical implications, it is believed that the here developed theoretical framework and the proposal of an assessment scale useful for analysing the phenomenon of contact with terrorism in the tourism context will contribute to develop better informed destination and business strategies in crisis situations .

\section{Limitations and Directions for Future Research}

This paper presents the development of a research instrument. Instead of treating contact with terrorism as a uni-dimensional construct, a three-dimensional construct is suggested, with various measurement units for each of the three sub-constructs being presented. TerrorScale is presented as a model with three first-order constructs: Direct Contact with Terrorism (TSC1), Indirect Contact with Terrorism (TSC2) and Attention to/ Interest in Terrorism on the Media (TSC3).

There are some limitations of the presented research approach to be considered. The first limitation is that the final instrument (i.e. the questionnaire) may have created common method variance that could have inflated construct relationships. This could be particularly threatening, if the respondents were 
aware of the conceptual framework of interest. However, they were not told the specific purpose of the study, and all of the construct items were separated and mixed so that no respondent should have been able to detect which items were affecting which factors.

Additionally, if common method bias exists, a CFA containing all constructs should produce a single method factor. The goodness-of-fit indices of this CFA (NFI=.39; CFI=.39, IFI=.39, TLI=.26) indicate a poor fit, which suggests that biasing from common method variance is unlikely. Hence, the biasing possibilities of common method variance were, it is expected, minimized. Second, while the reported research projects investigates contact of tourists travelling by plane with terrorism, care should be taken in extending the study beyond this specific research framework. Hence, although the fit indices suggest a good fit of the model to the data, future research is encouraged to test our instrument across other tourism settings and types of travelling. To do so, we encourage researchers to add new items and factors applicable to the research setting. Continued refinement of the TerrorScale proposed and supported in this study is certainly possible, based on further qualitative research. Finally, further research is required when analyzing the antecedents and consequences of TerrorScale. Thus, it is suggested to investigate how the contact with terrorism construct is associated with other variables, such as tourists' lifestyles, social, demographic and personality features.

\section{References}

Anderson, J., \& Gerbing, D. (1988). Structural Equation Modeling in Practice: A Review and Recommended Two-Step Approach. Psychological Bulletin, 103(3), 411-423.

Atkinson, S., Sandler, T., \& Tschirart, J. (1987). Terrorism in a Bargaining Framework. The Journal of Law and Economics, 30(1), 1-21.

Bagozzi, R. (1980). Causal Models in Marketing. New York: John Wiley.

Baral, A., Baral, S., \& Morgan, N. (2003). Marketing Nepal in an Uncertain Climate: Confronting Perceptions of Risk and Insecurity. Journal of Vacation Marketing, 10(5), 186-192.

Blake, A., \& Sinclair, M. (2003). Tourism Crisis Management: US Response to September 11. Annals of Tourism Research, 30(4), 813-832.

Blomberg, S., Hess, G., \& Orphanides, A. (2004). The Macroeconomic Consequences of Terrorism. Journal of Monetary Economics, 51, 1007-1032.

Brady, J., \& Widdows, R. (1988). The Impact of World Events on Travel to Europe During the Summer of 1986. Journal of Travel Research, 26(3), 8-10.

Bramwell, B., \& Rawding, L. (1996). Tourism Marketing Images of Industrial Cities. Annals of Tourism Research, 23(1), 201-221.

Bravo, A., \& Dias, C. (2006). An Empirical Analysis of Terrorism: Deprivation, Islamism, and Geopolitical Factors. Defence and Peace Economics, 17(4), 329-341.

Brunt, P., Mawby, R., \& Hambly, Z. (2000). Tourist Victimization and the Fear of Crime on Holiday. Tourism Management, 21(6), 417-424.

Cadogan, J., Diamantipoulos, A., \& Mortanges, C. (1999). A Measure of Export Market Orientation: Scale Development and Cross-Cultural Validation. Journal od International Business Studies, 30(4), 689-707.

Cavleck, N. (2002). Tour Operators and Destination Safety. Annals of Tourism Research, 29(2), 478496.

Chon, K. (1991). Tourism Destination Image Modification Process: Marketing Implications. Tourism Management, 12(1), 68-72.

Churchill, G. (1995). Marketing Research: Methodological Foundations. Chicago: The Dryden Press.

Coshall, J. (2003). The Threat of Terrorism as an Intervention on International Travel Flows. Journal of Travel Research, 42(1), 4-12. 
Crompton, J. (1979). An Assessment of the Image of Mexico as a Vacation Destination and the Influence of Geographical Location upon that Image. Journal of Travel Research, 17(Spring), $18-23$.

Cronbach, L. (1951). Coefficient Alpha and the Internal Structure of Tests. Psychometrika, 16, 297 334.

Cross, E., \& Chaffin, W. (1982). Use of the Binomial Theorem in Interpreting Results of Multiple Tests of Significance. Educational and Psychological Measurement, 42(2), 25-34.

Cutter, S., \& Willbanks, T. (2003). The Geographical Dimensions of Terrorism. New York: Routledge.

D'Amore, L., \& Anuza, T. (1986). International Terrorism: Implications and Challenge For Global Tourism. Business Quarterly, 4(November), 20-29.

Dann, G. (1993). Tourists' Images of a Destination - An Alternative Analysis. In D. Fesenmaier, J. O'Leary, \& M. Uysal (Edits.), Recent Advances in Tourism Marketing Research (pp. 41-55). New York: The Haworth Press.

Echtner, C., \& Ritchie, J. (1991). The Measurement of Destination Image: An Empirical Assessment. Journal of Travel Research, 3(2), 3-13.

Enders, W., \& Sandler, T. (1991). Causality Between Transnational Terrorism and Tourism: The Case of Spain. Terrorism, 14(1), 49-58.

Enders, W., Sandler, T., \& Parise, G. (1992). An Econometric Analysis of the Impact of Terrorism on Tourism. Kyklos, 45, 531-554.

Evans, N., \& Elphick, S. (2005). Models of Crisis Management: An Evaluation of theirs Value for Strategic Planning in the International Travel Industry. International Journal of Tourism Research, 7(13), 135-150.

Faulkner, B. (2001). Towards a Framework for Tourism Disaster Management. Tourism Management, 22(3), 135-147.

Fleisher, A., \& Buccola, S. (2002). War, Terror, and the Tourism Market in Israel. Applied Economics, 34(11), 1335-1343.

Fletcher, J., \& Morakabati, Y. (2008). Tourism Activity, Terrorism and Political Instability within Commonwealth: The Cases of Fiji and Kenya. International Journal of Tourism Research, 10, 537-556.

Fornell, C., \& Larcker, D. (1981). Evaluating Structural Equation Models with Unobservable Variables and Measurement Error. Journal of Marketing Research, 18(February), 39-50.

Gartner, W. (1989). Tourism Image: Attribute Measurement of State Tourism Products Using Multidimensional Scaling Techniques. Journal of Travel Research, 28(Fall), 16-20.

Gu, Z., \& Martin, T. (1992). Terrorism, Seasonality, and International Air Tourist Arrivals in Central Florida: An Empirical Analysis. Journal of Travel \& Tourism Marketing, 1(1), 3-15.

Gupta, S., Clements, B., Bhattacharya, R., \& Chakravarti. (2004). Fiscal Consequences of Armed Conflict and Terrorism in Low and Middle-Income Countries. European Journal of Political Economy, 20(4), 403-421.

Hall, C., \& O'Sullivan, V. (1996). Tourism, Political Stability and Violence. In A. Pizam, \& Y. Mansfeld (Edits.), Tourism, Crime and Security Issues (pp. 105-123). Chichester: Wiley.

Hartz, C. (1989). Business Executives as International Terrorist Targets. In J. Buckwalter (Ed.), International Terrorism: The Decade Ahead (pp. 21-28). Chicago: The University of Illinois at Chicago. Office of International Criminal Justice.

Hurley, J. (1988). The Hotels of Rome: Meeting the Marketing Challenge of Terrorism. The Cornell Quarterly, 29(1), 71-79. 
Jin, H. (2003). Compounding Consumer Interest. Journal of Advertising, 32(4), 29-41.

Jöreskog, K., \& Sorbom, D. (1996). LISREL 8: User's Reference Guide. Chicago: Scientific Software International.

Karber, P. (1971). Terrorism as a Social Protest. Unpublished paper cited in Sonmez (1998).

Krakover, S. (2000). Estimating the Effects of Atrocious Events on the Flow of Tourism in Israel. In G. Ashworth, \& R. Hartmann (Edits.), Tourism, War, and the Commemoration of Atrocity (pp. 37-56). New York: Cognizant Communication.

Le Billon, P. (2001). The Political Ecology of War: Natural Resources and Armed Conflicts. Political Geography, 20(3), 561-584.

Neumayer, F. (2004). The Impact of Political Violence on Tourism - Dynamic Cross-National Estimation. Journal of Conflict Resolution, 48, 259-281.

O'Connor, N., Stafford, M., \& Gallagher, G. (2008). The Impact of Global Terrorism on Ireland's Tourism Industry: An Industry in Perspective. Tourism and Hospitality Reserach, 8(4), 351364.

Paraskevas, A., \& Beverley, A. (2007). A Strategic Framework for Terrorism Prevention and Mitigation in Tourism Destinations. Tourism Management, 1, 1-14.

Pfefferbaum, B., Moore, V., McDonald, N., Maynard, B., Gurwitch, R., \& Nixon, S. (1999). The Role of Exposure in Post-Traumatic Stress in Youths Following the 1995 Bombing. Journal of the State Medical Association, 92, 164-167.

Pizam, A. (1999). A Comprehensive Approach to Classifying Acts of Crime and Violence at Tourist Destinations. Journal of Travel Research, 38(1), 5-12.

Pizam, A., Tarlow, P., \& Bloom, J. (1997). Making Tourists Feel Safe: Whose Responsability Is It? Journal of Travel Research, 3(3), 23-28.

Richter, L. (1983). Tourism Politics and Political Science: A Case of Not So Benign Neglect. Annals of Tourism Research, 10(3), 313-315.

Richter, L., \& Waugh, W. (1986). Terrorism and Tourism as Logical Companions. Tourism Management, 7(4), 230-238.

Ritchie, B. (2004). Chaos, Crises and Disasters: A Strategic Approach to Crisis Management in the Tourism Industry. Tourism Management, 25(5), 669-683.

Rohel, W., \& Fesenmaier, D. (1992). Risk Perceptions and Pleasure Travel: An Exploratory Analysis. Journal of Travel Research, 2(4), 17-26.

Russel, R., \& Faulkner, B. (2004). Entrepreneurship, Chaos and the Tourism Area Lifecycle. Annals of Tourism Research, 31(3), 556-579.

Schelenger, W., Caddell, J., Ebert, L., Jordan, B., Rourke, K., Wilson, D., . . . Kulka, R. (2002). Psychological Reactions to Terrorist Attacks: Findings from the National Study of Americans' Reactions to September 11. Journal of the American Medical Association, 288, 581-588.

Schuster, M., Stein, B., Jaycox, L., Collins, R., Marshall, G., Elliot, M., . . . Berry, S. (2001). A National Survey of Stress Reactions after the September 11, 2001, Terrorist Attacks. New England Journal of Medicine, 345(20), 1507-1512.

Seabra, C., Abrantes, J., \& Lages, L. (2007). The Impact of External Information Sources in Expectations Formation and Future Use of Media. Tourism Management, 28(6), 1541-1554.

Sommer, E., Ruvio, A., Soref, E., \& Sever, I. (2005). Terrorism, Distress and Coping: High Versus Low Impact Regions and Direct Versus Indirect Civilian Exposure. Anxiety, Stress and Coping, 18, 165-182. 
Sönmez, S. (1998). Tourism, Terrorism and Political Instability. Annals of Tourism Research, 25(2), 416-456.

Sönmez, S., \& Graefe, A. (1998a). Influence of Terrorism Risk on Foreign Tourism Decisions. Annals of Tourism Research, 25(1), 112-144.

Sönmez, S., \& Graefe, A. (1998b). Determining Future Travel Behavior From Past Travel Experience and Perceptions of Risk and Safety. Journal of Travel Research, 37(4), 171-177.

Sönmez, S., Apostolopoulos, \& Tarlow, P. (1999). Tourism and Crisis: Managing the Effects of Terrorism. Journal of Travel Research, 38(1), 13-18.

Spilerman, S., \& Stecklov, G. (2009). Societal Responses to Terrorist Attacks. Annual Review of Sociology, 35, 167-189.

Taylor, P. (2006). Getting Them to Forgive and Forget: Cognitive Based Marketing Responses to Terrorist Acts. International Journal of Tourism Research, 8, 171-183.

Tremblay, P. (1989). Pooling International Tourism in Western Europe. Annals of Tourism Research, 16(4), 477-491.

Um, S., \& Crompton, J. (1992). The Role of Perceived Inhibitors and Facilitators in Pleasure Travel Destination Decisions. Journal of Travel Research, 30(3), 18-25.

Uriely, N., Maoz, D., \& Reichel, A. (2007). Rationalising Terror-Related Risks: The Case of Israeli Tourists in Sinai. International Journal of Tourism Research, 9, 1-8.

VanRaaij, W., \& Francken, D. (1984). Vacation Decisions, Activities and Satisfactions. Annals of Tourism Research, 11(1), 101-112.

Weimann, G., \& Winn, C. (1994). The Theater of Terror: Mass Media and International Terrorism. New York: Longman.

Woodside, A., \& Lysonski, A. (1989). A General Model of Traveler Destinations Choice. Journal of Travel Research, 27(4), 8-14.

Yechiam, E., Barron, G., \& Erev, I. (2005). The Role of Personal Experience in Contributing to Different Patterns of Response to Rare Terrorist Attacks. Journal of Conflict Resolution, 49, 430-439. 
Appendix 1: Scales used in the study: initial and final scales

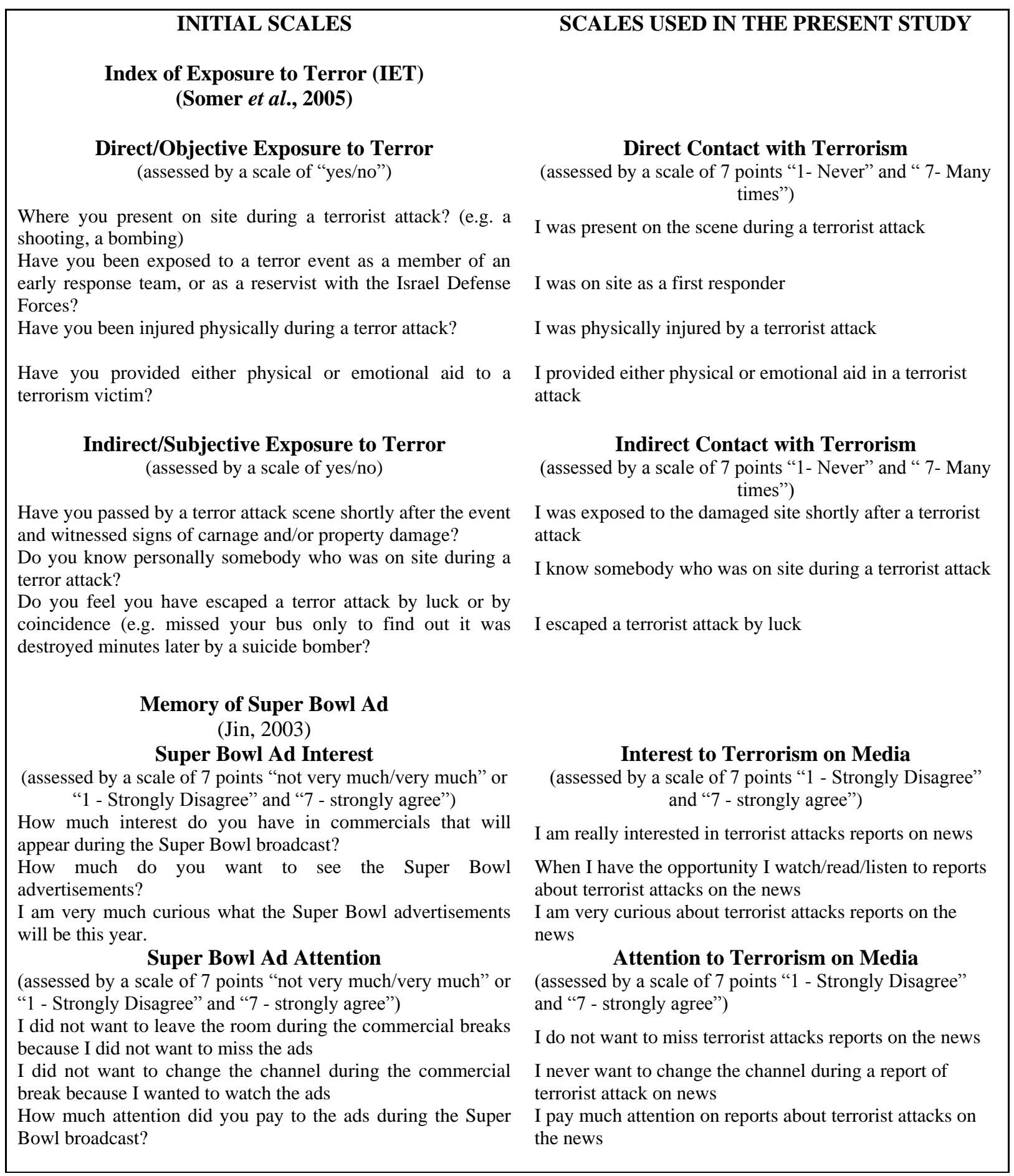

